\title{
VIABILITY EFFECTS AND RECOMBINATION DIFFERENCES IN A LINKAGE TEST WITH PALLID AND FIDGET IN THE HOUSE MOUSE
}

\author{
W. F. BODMER \\ Department of Genetics, University of Cambridge
}

\section{INTRODUCTION}

Received I I.v.6 I

THE recessive gene pallid ( $p a)$ (Roberts, 193I) causes a dilution of the coat colour, pink eyes and an abnormality of the labyrinth (Lyon, 1953). It has generally been found to reduce viability to some extent. Fidget $(f)$ is one of the "shaker" group of mutants. It is a recessive which was first described by Grüneberg (1943). Affected animals are generally smaller and weaker than normal mice in the early stages of their development. This results in a marked reduction in both their viability and fertility. The two genes are known to be situated in linkage group V (Roberts and Quisenberry, 1935; Carter and Grüneberg, 1950; Wallace, 1950).

The viability effects of $p a$ and $f i$ and the fact that they are linked make them well suited to an analysis of viability effects and interactions in a balanced linkage experiment, using the methods of analysis developed by Bodmer and Parsons (1959a,b) and Bodmer (1959). The only linkage test using both $p a$ and $f i$ is due to Carter (195I) and is based on intercrosses. This region of chromosome $\mathrm{V}$ is, however, one which has been subject to much investigation. Sex differences in recombination have been reported by Fisher and Landauer (1953), Wallace (1957) and Parsons (1958a), and an effect of age on recombination has been analysed by Fisher (1949). The purpose of this paper is to describe the results of a balanced backcross linkage test using these two factors $p a$ and $f$.

\section{METHOD}

It is difficult to breed reliably from fidget mice and Wallace (1957) was in fact the first person to use $f$ in backcross linkage tests. By a systematic programme of selection she was able to increase markedly their breeding performance. Combination of the $p a$ and $f i$ genes caused a further acute reduction in viability and fertility so that, to start with, pallid fidget mice were almost unobtainable and exceedingly weak. However, selection improved their performance so that it was possible to breed from both male and female pallid fidget mice. The stocks of pallid fidgets were maintained largely by coupling or single backcrosses. As was to be expected, it proved more difficult to obtain data from male heterozygotes, when the pallid fidget mice were the females, than from female heterozygotes with pallid fidget males. Adequately balanced data have thus only been obtained from the female coupling and repulsion heterozygotes $\left(\frac{p a f}{++}\right.$ and $\left.\frac{p a+}{+f}\right)$ and only a smaller amount of data was obtained from male coupling heterozygotes. 


\section{ANALYSIS OF THE DATA FROM FEMALE HETEROZYGOTES}

The improvement of the pallid and fidget viabilities by selection indicates the presence of some genetic variance affecting these characters. This should be demonstrable by variations in the proportion of fidgets and pallids between matings. The heterogeneity $\chi^{2} \mathrm{~s}$ for the ratios of fidget to non-fidget and pallid to non-pallid are shown for both coupling and repulsion series in table $\mathrm{I}$.

There is in both series of matings highly significant heterogeneity in the ratio of fidgets to non-fidgets but no evidence for heterogeneity in the ratios of pallids to non-pallids. Some of this variation may be due to the fact that data from different matings will not be balanced for the age of the mother and that viabilities may change significantly with the age of the mother, as will be discussed below. However, although it has not been possible to allow specifically for this, there

TABLE I

Tests for the heterogeneity between matings

\begin{tabular}{|l|c|c|}
\hline & Fidget : non fidget & Pallid : non-pallid \\
\hline Coupling & $\cdot$ & $\chi_{21}^{2}=38 \cdot 3403 \quad \mathrm{P} \approx$ I per cent. \\
$\chi_{18}^{2}=43 \cdot 7676 \quad \mathrm{P}<0 \cdot$ I per cent. & $\chi_{21}^{2}=19.4137$ \\
$\chi_{18}^{2}=19.54 \mathrm{I} 8$
\end{tabular}

seems to be no particular bias in the ages of parents which produced unusually high or low fidget ratios. Thus, there is at least suggestive evidence for some genetic control of the fidget viability. More significant evidence for such control with respect to fidget than to pallid is to be expected, as selection has been operating mainly to improve the fidget viability.

Truslove (1956) observed a similar heterogeneity in the proportion of fidgets in a series of backcrosses and intercrosses derived from outcrosses of Grüneberg's (1943) original fidget stock. She obtained a $\chi_{3}^{2}=7.78$ for the heterogeneity of the backcrosses and a $\chi_{4}^{2}=8.37$ for that of the intercrosses which together give a significance level of $2 \cdot 5$ per cent.

The combined data from repulsion and coupling matings are summarised in table 2.

Analyses of $\chi^{2}$ were performed on the original data (Bodmer and Parsons, I959a) and on the data after taking logarithms (Bodmer, I959) and these are shown in table 3. As would be expected, the recombination component is by far the largest in both analyses. There is also some lack of orthogonal balance indicated by the significant "heterozygotes" component. The viability $\times$ heterozygote and viability $\times$ recombination components are significant only on the $\chi^{2}$ 
analysis on the original data. Thus, although the 2-factor viability interaction is slightly inflated in the logarithmic analysis, a multiplicative model fits the data better than an additive model, as was predicted by Bodmer (I 959) and verified in Drosophila by Parsons (1959). The usual $2 \times 2$ contingency $\chi_{1}^{2}$ calculated from the "sums" square

TABLE 2

Combined data from coupling and repulsion female heterozygotes

\begin{tabular}{|c|c|c|c|c|c|}
\hline \multirow[b]{2}{*}{ Coupling } & \multirow[b]{2}{*}{. } & \multicolumn{2}{|c|}{ Non-recombinants } & \multicolumn{2}{|c|}{ Recombinants } \\
\hline & & $\stackrel{+}{f i p a}$ & $\begin{array}{r}22 \mathrm{I} \\
93\end{array}$ & $\begin{array}{c}p a \\
f i\end{array}$ & $\begin{array}{l}6 \mathrm{r} \\
59\end{array}$ \\
\hline Repulsion & . & $\begin{array}{c}p a \\
f i\end{array}$ & $\begin{array}{l}145 \\
125\end{array}$ & $\stackrel{+}{f i p a}$ & $\begin{array}{l}7^{6} \\
25\end{array}$ \\
\hline
\end{tabular}

for detecting 2-factor viability interactions, is 0.02 and in this case agrees more closely with the result from the additive analysis. However, it may well be that a multiplicative model with some slight viability interaction gives a more accurate representation of the underlying situation than an additive model with no viability interaction but

TABLE 3

Chi-squared analysis of data from female heterozygotes

\begin{tabular}{|c|c|c|c|c|c|c|}
\hline & & d.f. & $\begin{array}{c}\text { Original } \\
\text { data } \\
\chi^{2}\end{array}$ & $\begin{array}{c}\mathrm{P} \text { in } \\
\text { per cent. }\end{array}$ & $\begin{array}{c}\text { Logarithmic } \\
\text { data } \\
\chi^{2}\end{array}$ & $\begin{array}{c}\mathrm{P} \text { in } \\
\text { per cent. }\end{array}$ \\
\hline \multicolumn{7}{|l|}{ Latin square of sums } \\
\hline Heterozygotes & . & I & $4 \cdot 93$ & $5-2 \cdot 5$ & $7 \cdot 36$ & $1-0.5$ \\
\hline Recombination & . & I & I 63.69 & $<\ddot{<}<0 . \mathrm{I}$ & $20 \mathrm{I} \cdot 05$ & $<<<0.1$ \\
\hline 2 -factor viability interaction & . & I & 0.78 & ... & $3 \cdot 3 I$ & I 0.5 \\
\hline \multicolumn{7}{|l|}{ Latin square of differences } \\
\hline Viability $\times$ heterozygote & . & I & $4 \cdot 3^{2}$ & $5^{-2} \cdot 5$ & $I \cdot 65$ & $\cdots$ \\
\hline Viability $\times$ recombination & . & I & I I $\cdot 21$ & $<0^{\prime} \mathrm{I}$ & $0.2 \mathrm{I}$ & $\cdots$ \\
\hline Main viability effect of $p a$ & . & I & $30 \cdot 62$ & $<<0 \cdot 1$ & $40 \cdot 56$ & $<<0 \cdot \mathrm{I}$ \\
\hline \multirow[t]{2}{*}{ Main viability effect of $f l$} & . & I & $50 \cdot 19$ & $<<0 \cdot \mathrm{I}$ & $58 \cdot 63$ & $<<\mathrm{O}^{\cdot} \mathrm{I}$ \\
\hline & & 7 & & & & \\
\hline
\end{tabular}

with spurious viability $\times$ heterozygote and viability $\times$ recombination interactions.

The estimate of the recombination fraction using the product formula (Fisher, I 935 and later) is $27.44 \mathrm{I} 6$ per cent. $\pm \mathrm{I} \cdot 585$ per cent. This is somewhat higher than the value of 19 per cent. \pm 3.6 per cent. obtained by Carter ( I 95 I). However, his estimate was based on intercross data and is thus likely to be severely disturbed by any viability differences. Following Bodmer and Parsons ( $1959 b$ ) it is possible to estimate 
the viabilities of pallid and fidget assuming a multiplicative model, a procedure which is similar to the estimation of the recombination fraction using a product formula. The estimate of the fidget viability is $5^{8.68}$ per cent. $\pm 5^{\circ}$ o I per cent. and of the pallid viability 64.39 per cent. \pm 5.50 per cent. As expected, both the fidget and pallid conditions cause severe reductions in viability. It is interesting to note that the viability estimates obtained in the usual way from the over-all proportions of fidgets and pallids are $75^{\circ} .03$ per cent. \pm 3.42 per cent. and 80.50 per cent. \pm 3.46 per cent. respectively, which just about differ at a 5 per cent. significance level from the multiplicative estimates.

TABLE 4

Combined data from female heterozygotes tabulated according to the age of the maternal parent

\begin{tabular}{|c|c|c|c|c|c|c|c|c|}
\hline \multirow{2}{*}{ Age in months } & \multirow{2}{*}{$\begin{array}{c}\text { Total } \\
\text { No. }\end{array}$} & \multirow{2}{*}{$\begin{array}{l}\text { No. of } \\
\text { litters }\end{array}$} & \multicolumn{2}{|c|}{ Fidgets } & \multicolumn{2}{|c|}{ Pallids } & \multicolumn{2}{|c|}{ Recombinants } \\
\hline & & & No. & $\%$ & No. & $\%$ & No. & $\%$ \\
\hline 2 & II 5 & $2 I$ & 44 & 38.2 & 27 & 20.0 & & \\
\hline 3 & 84 & I9 & 45 & $53 \cdot 6$ & 35 & $4 I \cdot 7$ & $\begin{array}{l}31 \\
26\end{array}$ & 30.9 \\
\hline 4 & І 06 & 17 & 45 & $4^{2} \cdot 5$ & 45 & $42 \cdot 5$ & 26 & $24 \cdot 5$ \\
\hline 5 & $9^{8}$ & I 8 & 35 & 35.7 & 37 & $37 \cdot 8$ & 28 & $28 \cdot 6$ \\
\hline 6 & I08 & 17 & 39 & $36 \cdot I$ & $5^{2}$ & $4^{8 \cdot 2}$ & 37 & $34 \cdot 3$ \\
\hline 7 & 73 & I 5 & $3^{I}$ & $4^{2} \cdot 5$ & 35 & $47 \cdot 9$ & 17 & $23 \cdot 3$ \\
\hline 8 & $9^{2}$ & I9 & $3^{2}$ & $34 \cdot 8$ & 36 & $39 \cdot I$ & 22 & 23.9 \\
\hline 9 & 42 & Io & $12 !$ & & I8) & & I0! & \\
\hline 10 & $3^{8}$ & Io & Iof & $2 / 3$ & I5! & 412 & $8 j$ & 223 \\
\hline I I & 24 & 7 & 61 & & 10। & & $5)$ & \\
\hline 12 & 8 & 3 & I & $18 \cdot 4$ & 3 & $28 \cdot 6$ & $4\}$ & 20.4 \\
\hline \multirow[t]{2}{*}{$>12$} & I 7 & 7 & 2) & & 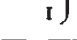 & & I) & \\
\hline & 805 & 163 & 302 & $\ldots$ & 324 & $\cdots$ & 22 I & $27 \cdot 45$ \\
\hline
\end{tabular}

The good fit of the logarithmic $\chi^{2}$ analysis makes it almost certain that the multiplicative estimates provide a more genuine measure of the fidget and pallid viabilities.

Perhaps the most interesting aspect of the data is revealed by an analysis of the effect of the age of the maternal parent on the viabilities and on the recombination fraction. A summary of the combined coupling and repulsion data subdivided according to the age of the female parent is given in table 4. It is immediately apparent that there is a marked reduction in fidget viability with increasing age of mother, a similar but less marked reduction in the pallid viability and in the recombination fraction. Although, as pointed out above, the proportion of fidgets and pallids may not be very satisfactory estimates of the viabilities, these proportions are the only practicable measures which can be used for a regression analysis. Following Fisher (I949) the proportions were first transformed by the angular transformation $\left(\sin ^{2} \Phi=\rho\right)$, so that the variance attached to any value depends only 
on the observed total. An analysis of variance can then be performed on the transformed angular values. For this purpose the data for ages 9 and 10 months were combined, as were the data for all ages greater than or equal to II months.

A $\chi_{1}^{2}$ for linear regression was calculated from a straightforward weighted linear regression analysis as described by Fisher (1949). An approximate $\chi_{1}^{2}$ for quadratic regression was calculated by giving equal weight to the observations from different ages and using orthrogonal polynomials in the usual way (Fisher and Yates, 1957). The theoretical variance of the angular values was then calculated from the harmonic mean of the observed totals for the different maternal ages. The residual $\chi^{2}$ was obtained by subtraction. The resulting regression analysis is given in table 5 .

TABLE 5

Analysis of regression of viabilities and recombination fraction with maternal age

\begin{tabular}{|c|c|c|c|c|c|}
\hline & & & $\begin{array}{l}\text { Fidget } \\
\text { viability }\end{array}$ & $\begin{array}{l}\text { Pallid } \\
\text { viability }\end{array}$ & $\begin{array}{l}\text { Recombination } \\
\text { fraction }\end{array}$ \\
\hline Linear regression & . & $\chi_{i}^{2}$ & $13 \cdot 77^{* * *}$ & 0.02 & $4 \cdot 08^{*}$ \\
\hline Quadratic regression + & . & $\chi_{\mathrm{i}}^{2}$ & $4 \cdot 20^{*}$ & $8 \cdot 10^{* *}$ & $0 \cdot 18$ \\
\hline Residual . & - & $\chi_{6}^{2}$ & $6 \cdot 00$ & $3 \cdot 01$ & $4 \cdot 47$ \\
\hline
\end{tabular}

*** $\mathbf{P}<0.1$ per cent., ** 0.5 per cent. $>\mathbf{P}>0.1$ per cent., ${ }^{*} 5$ per cent. $>\mathbf{P}>\mathbf{2} \cdot 5$ per cent.

$\dagger$ Approximate test giving equal weight to observations from different ages (see text for explanation).

All analyses were performed after applying the angular transformation.

The linear regression of recombination fraction with increasing maternal age is significant at the 5 per cent. level and there is no evidence for a quadratic component or any significant departure from linearity. Variation in recombination with maternal age is well known in Drosophila and was first described by Bridges (1915). According to Bridges (1929) there is an initial decrease in recombination with a minimum at 9-I I days but then further increases and decreases giving a W-shaped curve of variation. The only other significant downward trend of recombination with maternal age in mice is reported by Fisher (1949). Wallace (1957) points out that her data, Fisher's data and that quoted by Owen (1953) all give U-shaped curves for the first 9 months, but such variation could hardly be judged to be significant.

The linear regression of fidget viability with maternal age is highly significant. The quadratic regression is significant at the 5 per cent. level, but not too much weight must be placed on this as the calculated $\chi_{1}^{2}$ is an approximate one. The pallid viability, however, shows no 
significant linear regression but a highly significant quadratic regression whose significance is not likely to be materially affected by the approximations used. It is well known that average litter size decreases with maternal age and it seems worth noting that the deterioration in fidget viability apparently starts before the major decrease in litter size.

Extensive human data on birth weight and gestation time in relation to maternal age, parity and infant survival have been analysed by Karn and Penrose (195I). They showed that birth weight increases with parity and that weights somewhat less than the maximum were most favourable to survival. Thus probability of survival showed parabolic variation with parity. It is of interest that pallid viability and perhaps also fidget viability show a similar parabolic variation with maternal age. No attempt has been made with these data to separate the effects of maternal age and parity, but the two are, of course, highly correlated. Certainly fidget and, to a lesser extent, pallid reduce birth weight so that an initial increase in birth weight with maternal age may well account for the initial increase in viability. The subsequent decrease is, presumably, due to a general deterioration of the in utero environment with increasing maternal age.

\section{ANALYSIS OF THE DATA FROM MALE COUPLING HETEROZYGOTES}

The smaller body of data that was obtained from male coupling heterozygotes showed no heterogeneity with respect to the proportions of either fidgets or pallids. The data are summarised in table 6 .

TABLE 6

Summary of data from male coupling heterozygotes

\begin{tabular}{|c|c|c|c|c|}
\hline+ & $p a$ & $f$ & $p a, f i$ & Total \\
\hline 66 & 19 & 10 & 22 & 117 \\
\hline
\end{tabular}

Recombination fraction : $26 \cdot 57$ per cent. $\pm 4 \cdot 30$ per cent. Fidget viability : $\quad 4 \mathrm{I} \cdot 88$ per cent. $\pm 9 \cdot 67$ per cent. Pallid viability : $\quad 79.5^{8}$ per cent. $\pm 18.3^{8}$ per cent.

All estimates were obtained using a product formula (Fisher, 1935 and later).

The estimate of the recombination fraction, using a product formula and ignoring the possibility of viability interactions, is 26.57 per cent. \pm 4.30 per cent. This is slightly lower than the value given by the female heterozygotes, but the difference is far from significant. Sex differences in this region of linkage group $\mathrm{V}$ have been summarised and discussed by Wallace (1957). She pointed out that recombination fractions on the $p a$ side of the $f i$ locus were lower in males than in females but that her data for the region $f i-S d$, on the other side of $f i$, gave a 
higher recombination fraction in the males. However, the sex difference for the $f i-S d$ region was not significant. Similar differences were obtained by Parsons (1958a) using the markers Ragged, agouti, and wellhaarig also on linkage group V. The only significant sex differences (Fisher and Landauer, I953; Owen, 1953) on this chromosome give a lower value for the males and the data presented here do not contradict this. A significant sex difference with a higher recombination fraction in the males has, however, been reported by Mallyon (195I) for markers on another chromosome. It is in fact well known that variation in recombination, from whatever cause, is generally more marked for regions near the centromere (see, e.g. Parsons, I 958b). In fact Parsons (1958b) used evidence from sex differences in recombination to help in attempting to place the centromere in linkage group XIII of the mouse. It might therefore be expected that a region showing a marked effect of maternal age would be one near the centromere and so would also show a sex difference. It seems worth noting that the data presented here contradict this expectation.

Estimates of the fidget and pallid viabilities using a product formula are $4^{\mathrm{I}} \cdot 88$ per cent. $\pm 9^{.} 67$ per cent. and $79^{.} 5^{8}$ per cent. $\pm 18.3^{8}$ per cent. respectively. These values show a striking difference from the estimates obtained from the female heterozygote data. The fidget viability is much lower but the pallid viability is higher. The difference in the pallid viabilities does not approach significance but the difference in the fidget viabilities is suggestive giving a significance level of 13.4 per cent. It should be pointed out that all the data which have been presented in this paper refer only to mice which have been classified with certainty for both pallid and fidget. Pallid is easily classifiable at birth. Fidget, however, is not usually classifiable with certainty until the mice are two or more weeks old. The procedure that has been followed, in general, is to do a provisional classification at an early age and to check this later. There is some mortality between these two classifications but it would seem that most of the elimination occurs either in utero or at a very early age, perhaps at birth. Mice lost at birth are generally eaten by the parents so that it is not practicable to obtain an estimate of the proportion lost at this stage. The average number of mice per litter which reached the age at which they could be classified with certainty was 4.94 from the female heterozygotes but only 3.34 from male heterozygotes, when the mothers were pallid fidgets. The poorer fertility of the pallid fidget females seems to be associated with a reduced fidget viability and, perhaps, compensated by an increased pallid viability.

\section{DISCUSSION}

The order of the loci on linkage group V is a-un-we-pa-fi-Sd. Data from experiments with the loci $a$, un, we, $p a$ (Fisher, I949; Fisher and Landauer, 1953; Owen, 1953) suggest a combined map length for the 
region $a$-pa of about $16 \mathrm{~cm}$. Wallace (1957) obtained an estimate of about $44 \mathrm{~cm}$. for the $a-f i$ map length assuming that interference follows Kosambi's rule (Kosambi, I 944; Owen, I950). The $p a-f$ recombination fraction of about 27 per cent., reported in this paper, fits in well with these estimates of map length. There is little doubt that the theory of interference first proposed by Fisher, Lyon and Owen (I947) and later elaborated by Owen (1950, I953 and other papers) provides a useful tool for the construction of genetic maps in an organism like the mouse where it is not possible to cover a chromosome with a series of closely linked markers. However, it seems unlikely that extensive linkage experiments in mice will throw much further light on the phenomena of recombination and interference.

The relevance of the findings on variation in viability and recombination with maternal age to studies on the incidence of human congenital abnormalities has been discussed in a preliminary communication of these data (Bodmer, 196I). Mongolism in man is now known to be caused by aneuploidy for one of the smaller somatic chromosomes (Lejeune, Turpin and Gautier, I959). This is most probably the result of meiotic non-disjunction for the relevant chromosome. Mongolism is also well known to increase markedly in incidence with increasing maternal age (see, e.g. Penrose, 1934). Early work with Drosophila showed a clear relationship between non-disjunction and recombination (see Mather, I 938). An increase of non-disjunction is generally associated with a decrease in crossing over and the two have a common origin in the restriction of pairing. Thus the increase in the incidence of mongolism with maternal age in humans, reflecting an increase in the frequency of non-disjunction, and the decrease in the frequency of recombination with maternal age in mice may well have a common origin in the effect of maternal age on the efficiency of pairing at meiosis. In plants Rees and Naylor (I960) have shown that developmental variation within an anther may be associated with highly significant differences in the frequency of chiasma formation. Chiasma formation and chromosome pairing may clearly be considerably affected by developmental differences such as might occur in the ovum of the ageing mother. In fact Polani et al. (I960) have suggested a specific mechanism for the way this might happen, in terms of the possible effects of maternal age on the nucleolar organiser which is on the chromosome associated with mongolism.

Many congenital abnormalities of the nervous system in humans are known to increase in incidence with increasing maternal age. (See, e.g. Penrose, 1939; Edwards, 1958.) Such developmental abnormalities are generally considerably subject to environmental influences (Edwards, I958) and cannot be explained by any simple genetic hypothesis. In general it seems unlikely that any congenital abnormality associated with a single gene difference should show an increased incidence with increasing maternal age, for such factors are likely to be associated with fairly severe viability disturbances, although 
perhaps not so severe as in mice because of the lack of intra-uterine competition. By analogy with the situation for fidget and pallid in mice, we might expect such viability disturbances to reduce incidence, at least for the later maternal age groups.

The value of data from laboratory animals for the interpretation of the incidence of congenital abnormalities in humans was early pointed out by Wright (1926). This has been emphasised more recently by Holt (I948) and Searle (I959) but still does not seem to be fully appreciated.

It is worth noting that with linked factors the only satisfactory experimental design for obtaining information on viability effects is the balance backcross linkage test. A serious limitation of this sort of data, however, lies in the complicated circumstances which result in an observed viability deficiency and our almost complete ignorance of the physiological and biochemical bases of such genetic defects.

\section{SUMMARY}

I. Data are presented from a linkage test with the factors pallid and fidget on linkage group $\mathrm{V}$ of the house mouse. The data from female heterozygotes are balanced but there are only data from male coupling heterozygotes.

2. There is significant heterogeneity between matings in the ratio of fidgets to non-fidgets but no heterogeneity in the ratio of pallids to non-pallids. This supports the suggestion that there is some measure of genetic control of the fidget viability.

3. The data from female heterozygotes are analysed by the methods of Bodmer and Parsons (1959a) and Bodmer (1959) and support a "multiplicative" model.

4. The estimate of the recombination fraction in females $(27.44$ per cent. $\pm \mathrm{I} .59$ per cent.) does not differ significantly from that in males (26.57 per cent. $\pm 4.3^{8}$ per cent.). The values agree with previous estimates of map length for this region of linkage group $\mathrm{V}$.

5. There is evidence for a significant decrease in recombination fraction with the age of the maternal heterozygous parent. There is also a very significant linear decrease in fidget viability with maternal age. The pallid viability and, to a lesser extent, the fidget viability, show significant parabolic variation with maternal age.

6. Multiplicative estimates of the fidget and pallid viabilities from the female data are $5^{8.68}$ per cent. $\pm 5^{\circ}$ or per cent. and 64.39 per cent. \pm 5.50 per cent. respectively. The estimates from the male data are $4 \mathrm{I} \cdot 88$ per cent. $\pm 9 \cdot 67$ per cent. and $79.5^{8}$ per cent. $\pm 18 \cdot 3^{8}$ per cent. respectively.

7. The relevance of the data on variation in viability and recombination with maternal age to studies on the incidence of congenital abnormalities in humans, is discussed. The value of studies with mice in helping to interpret such phenomena in humans is emphasised. 
Acknowledgments.-I am grateful to Professor Sir Ronald Fisher, F.R.s., for first suggesting this problem to me and to Mrs M. E. Wallace for helpful discussions during the earlier parts of the investigation. I am also grateful to Professor K. Mather, F.R.s. and Dr J. L. Jinks, for helpful criticism of the manuscript and for drawing my attention to the relationship between crossing-over and non-disjunction. The receipt of an Agricultural Research Council studentship during part of this investigation is gratefully acknowledged.

\section{REFERENCES}

BODMER, W. F. 1959. Multiplicative effects and the logarithmic transformation in the analysis of balanced multi-point linkage tests. Heredity, I3, 157-1 64 .

BoDMER, W. F. 1961. Effects of maternal age on the incidence of congenital abnormalities in mouse and man. Nature, Lond., I90, 11 $34^{-1} 135$.

Bodmer, W. F., AND PARSONs, P. A. 1959a. The analogy between factorial experimentation and balanced multi-point linkage tests. Heredity, $13,145-156$.

BODMER, W. F., AND PARSONS, P. A. 1959 $b$. Factorial analysis of balanced four and higher-point linkage tests. Heredity, ${ }_{3}, 487-498$.

BRIDGES, C. B. 1915. A linkage variation in Drosophila. 7. Exp. Zool., I9, I-2 I.

BRIDGES, с. B. 1929. Variation in crossing-over in relation to age of female in Drosophila melanogaster. Carnegie Institute, Washington, 399, 63-89.

CARTER, T. C. 195I. The position of fidget in linkage group V of the house mouse. 7. Genet., 5o, 264-267.

CARTER, T. C., AND GRÜNEBERG, H. 1950. Linkage between fidget and agouti in the house mouse. Heredity, 4, 373-376.

EDWARDS, J. H. 1958. Congenital malformations of the central nervous system in Scotland. Brit. 7. prev. soc. med., 12, $115^{-1} 3^{3}$.

FISHER, R. A. 1935 and later. Statistical Methods for Research Workers. Edinburgh, Oliver and Boyd.

FISHER, R. A. 1949. A preliminary linkage test with agouti and undulated mice. Heredity, 3, 229-24I.

FISHER, R. A., AND LANDAUER, w. 1953. Sex differences of crossing-over in close linkage. Amer. Nat., 87, I 6 .

FISHER, R. A., LYON, M. F., AND OWEN, A. R. G. 1947. The sex chromosome in the house mouse. Heredity, $x, 355-365$.

Fisher, R. A., AND yATES, F. 1957. Statistical Tables for Biological, Agricultural and

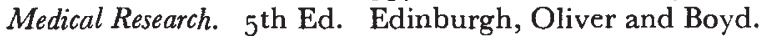

GRÜNEBERG, H. 1943. Two new genes in the house mouse. 7. Genet., 45, 22-28.

ноLт, s. в. 1948. The effect of maternal age on the manifestation of a polydactyl gene in mice. Ann. Eugen. Lond., 14, 144-157.

KARN, M. N., AND PENROSE, L. S. 1951. Birth weight and gestation time in relation to maternal age, parity, and infant survival. Ann. Eugen., Lond., I6, 147-164.

KosAMBI, D. D. 1944. The estimation of map distances from recombination values. Ann. Eugen., Lond., 12, I72-175.

LEJEUNE, J., TURPIN, R., AND GAUTIER, M. 1959. Le mongolisme, premier example d'aberration autosomique humaine. Ann. Genet., 2, 4 I.

LYON, M. F. 1953. Absence of otoliths in the mouse : an effect of the pallid gene in the house mouse. 7. Genet., 5I, 638-650.

MALLYoN, S. A. I951. A pronounced sex difference in recombination values in the sixth chromosome of the house mouse. Nature, 168 , I 18.

MATHER, K. 1938. Crossing over. Biol. Rev., 13, 252-292.

owen, A. R. G. 1950. The theory of genetical recombination. Advances in Genetics, 3, II 7-157.

OWEN, A. R. G. 1953. The analysis of multiple linkage data. Heredity, 7, 247-264. PARsons, P. A. 1958a. Additional three-point data for linkage group $\mathrm{V}$ of the mouse. Heredity, 12, 357-362. 
PARSONS, P. A. 1958b. A balanced four-point linkage experiment for linkage group XIII of the house mouse. Heredity, 12, 77-95.

PARsons, P.A. 1959. Multiplicative gene action in Drosophila linkage data. Genetica, 30, 190-200.

PENROSE, L. S. 1934. The relative aetiological importance of birth order and maternal age in mongolism. Proc. Roy. Soc. B., II5, $431-450$.

PENROSE, L. S. 1939. Maternal age, order of birth and developmental abnormalities. 7. Ment. Sci., Nov. I-10.

polani, P. E., BRigGs, J. H., Ford, C. E., Clarke, C. M., AND berG, J. M. ig6o. A Mongol girl with 46 chromosomes. Lancet, i, 72 I-724.

REES, H., AND NAYLOR, B. 1960. Developmental variation in chromosome behaviour. Heredity, $15,17-27$.

ROBERTS, E. I931. A new mutation in the house mouse (Mus musculus). Science, 74,569 .

ROBERTS, E., AND QUISENBERRY, J. H. 1935. Linkage of the genes for non-yellow $(y)$ and pink-eye 2 in the house mouse. Amer. Nat., 69, 181-183.

SEARLE, A. G. 1959. The incidence of anencephaly in a polytypic population. Ann. Hum. Genet. Lond., 23, 279-288.

truslove, G. m. 1956. The anatomy and development of the fidget mouse. $\mathcal{F}$. Genet., 54, 64-86.

wALlace, M. E. 1950. The locus of the gene "fidget" in the house mouse. Nature, Lond., $166,407$.

WALlAGE, M. E. I957. A balanced three-point linkage experiment for linkage group $\mathrm{V}$ of the house mouse. Heredity, II, 223-258.

WRIGHT, S. 1926. Effects of age of parents upon characteristics of the guinea-pig. Amer. Nat., 6o, 552-559. 